References:

[1] Denry, I. \& Holloway, J. A. (2014). "Low temperature sintering of fluorapatite glass-ceramics,” Dental Materials, 30(2), 112-121.

[2] Hill, R. \& Calver, A. (2007). "Real-time nucleation and crystallization studies of fluorapatite glass-ceramics using smallangle neutron scattering and neutron diffraction," Journal of the American Ceramics Society, 90(3), 763-768.

Keywords: glass-ceramics, small-angle scattering, fluorapatite

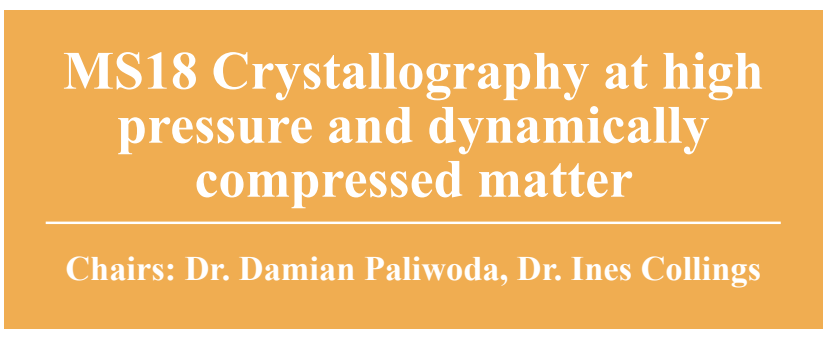

MS18-01

\section{X-Ray diffraction studies of mineral phase transitions under shock compression}

\author{
Sally June Tracy ${ }^{1}$ \\ 1. Geosciences, Princeton University, Princeton, United States of \\ America \\ email: sjtracy@princeton.edu
}

Laboratory shock wave experiments have long played an important role in the study of geological materials under extreme pressure and temperature conditions. Shock compression experiments provide the unique capability to study impact phenomena in real time and allow for measurements of equations of state and phase transitions. However, a limitation of continuum shock wave studies is that the crystal structure of high-pressure phases formed under dynamic compression is generally not known. This talk will focus on new experiments carried out at the Dynamic Compression Sector (DCS) of the Advanced Photon Source. DCS couples gun-based dynamic compression platforms with time-resolved synchrotron X-ray diffraction. This allows for an in situ study the crystal structure of minerals shocked into the high pressure and high temperature conditions that occur in the Earth's interior or during meteorite impacts. The diffraction data are combined with continuum-level measurements to reveal a complete picture of the material response from the atomic length scale to the continuum level, allowing for the unambiguous determination of the phase(s) formed under shock compression at $\sim 100 \mathrm{~ns}$ timescales. This talk will review recent experiments carried out at DCS on materials including $\mathrm{SiO}_{2}, \mathrm{TiO}_{2}$ and $\mathrm{ZnO}$. The resulting diffraction patterns are used to identify the high-pressure mineral structures and texture analysis of data for shocked single crystals can provide insight into transformation pathways between low- and high-pressure phases. The findings improve our understanding of minerals in the Earth's deep interior and allow us to better understand crystal structure modifications that occur in shocked minerals during meteorite impact events.

Keywords: shock, Hugoniot 